\title{
Identification of EGFLAM, SPATC1L and RNASE13 as novel susceptibility loci for aortic aneurysm in Japanese individuals by exome-wide association studies
}

\author{
YOSHIJI YAMADA $^{1,2}$, JUN SAKUMA $^{2-4}$, ICHIRO TAKEUCHI ${ }^{2,4,5}$, YOSHIKI YASUKOCHI ${ }^{1,2}$, \\ KIMIHIKO KATO $^{1,6}$, MITSUTOSHI OGURI ${ }^{1,7}$, TETSUO FUJIMAKI ${ }^{8}$, HIDEKI HORIBE ${ }^{9}$, \\ MASAAKI MURAMATSU ${ }^{10}$, MOTOJI SAWABE ${ }^{11}$, YOSHINORI FUJIWARA ${ }^{12}$, YU TANIGUCHI ${ }^{12}$, \\ SHUICHI OBUCHI ${ }^{13}$, HISASHI KAWAI ${ }^{13}$, SHOJI SHINKAI ${ }^{14}$, \\ SEIJIRO MORI $^{15}$, TOMIO ARAI ${ }^{16}$ and MASASHI TANAKA ${ }^{17}$ \\ ${ }^{1}$ Department of Human Functional Genomics, Advanced Science Research Promotion Center, \\ Mie University, Tsu, Mie 514-8507; ${ }^{2}$ CREST, Japan Science and Technology Agency, Kawaguchi 332-0012; \\ ${ }^{3}$ Computer Science Department, College of Information Science, University of Tsukuba, Tsukuba 305-8573; \\ ${ }^{4}$ RIKEN Center for Advanced Intelligence Project, Tokyo 103-0027; ${ }^{5}$ Department of Computer Science, \\ Nagoya Institute of Technology, Nagoya 466-8555; ${ }^{6}$ Department of Internal Medicine, Meitoh Hospital, \\ Nagoya 465-0025; ${ }^{7}$ Department of Cardiology, Kasugai Municipal Hospital, Kasugai 486-8510; ${ }^{8}$ Department of \\ Cardiovascular Medicine, Inabe General Hospital, Inabe 511-0428; 9 Department of Cardiovascular Medicine, \\ Gifu Prefectural Tajimi Hospital, Tajimi 507-8522; ${ }^{10}$ Department of Molecular Epidemiology, Medical Research Institute, \\ Tokyo Medical and Dental University, Tokyo $101-0062 ;{ }^{11}$ Section of Molecular Pathology, \\ Graduate School of Health Care Sciences, Tokyo Medical and Dental University, Tokyo 113-8510; \\ ${ }^{12}$ Research Team for Social Participation and Community Health, ${ }^{13}$ Research Team for Promoting Support System \\ for Home Care, and ${ }^{14}$ Research Team for Social Participation and Health Promotion, Tokyo Metropolitan \\ Institute of Gerontology; ${ }^{15}$ Center for Promotion of Clinical Investigation, ${ }^{16}$ Department of Pathology, and \\ ${ }^{17}$ Department of Clinical Laboratory, Tokyo Metropolitan Geriatric Hospital, Tokyo 173-0015, Japan
}

Received January 27, 2017; Accepted March 7, 2017

DOI: $10.3892 /$ ijmm.2017.2927

\begin{abstract}
We performed an exome-wide association study (EWAS) toidentify genetic variants - in particular,low-frequency or rare variants with a moderate to large effect size - that confer susceptibility to aortic aneurysm with 8,782 Japanese subjects (456 patients with aortic aneurysm, 8,326 control individuals) and with the use of Illumina HumanExome-12 DNA Analysis BeadChip or Infinium Exome-24 BeadChip arrays. The correlation of allele frequencies for 41,432 single nucleotide polymorphisms (SNPs) that passed quality control to aortic aneurysm was examined with Fisher's exact test. Based on Bonferroni's correction, a P-value of $<1.21 \times 10^{-6}$ was considered statistically significant. The EWAS revealed 59 SNPs that were significantly associated with aortic aneurysm. None of these
\end{abstract}

Correspondence to: Professor Yoshiji Yamada, Department of Human Functional Genomics, Advanced Science Research Promotion Center, Mie University, 1577 Kurima-machiya, Tsu, Mie 514-8507, Japan

E-mail: yamada@gene.mie-u.ac.jp

Key words: aortic aneurysm, dissecting aneurysm, genetics, exome-wide association study, polymorphism
SNPs was significantly $\left(\mathrm{P}<2.12 \times 10^{-4}\right)$ associated with aortic aneurysm by multivariable logistic regression analysis with adjustment for age, gender and hypertension, although 8 SNPs were related $(\mathrm{P}<0.05)$ to this condition. Examination of the correlation of these latter 8 SNPs to true or dissecting aortic aneurysm separately showed that rs1465567 [T/C (W229R)] of the EGF-like, fibronectin type III, and laminin $\mathrm{G}$ domains gene $(E G F L A M)$ (dominant model; $\mathrm{P}=0.0014$; odds ratio, 1.63) was significantly $(\mathrm{P}<0.0016)$ associated with true aortic aneurysm. We next performed EWASs for true or dissecting aortic aneurysm separately and found that 45 and 19 SNPs were significantly associated with these conditions, respectively. Multivariable logistic regression analysis with adjustment for covariates revealed that rs113710653 [C/T (E231K)] of the spermatogenesis- and centriole associated 1-like gene (SPATC1L) (dominant model; $\mathrm{P}=0.0002$; odds ratio, 5.32) and $\mathrm{rs} 143881017$ [C/T $(\mathrm{R} 140 \mathrm{H})]$ of the ribonuclease A family member 13 gene (RNASE13) (dominant model; $\mathrm{P}=0.0006$; odds ratio, 5.77) were significantly $\left(\mathrm{P}<2.78 \times 10^{-4}\right.$ or $\mathrm{P}<6.58 \times 10^{-4}$, respectively) associated with true or dissecting aortic aneurysm, respectively. EGFLAM and SPATC1L may thus be susceptibility loci for true aortic aneurysm and RNASE13 may be such a locus for dissecting aneurysm in Japanese individuals. 


\section{Introduction}

Aortic aneurysm is a serious condition that results from an atherosclerotic aorta and is a leading cause of mortality in humans (1). Studies on the genetic basis of familial aortic aneurysm have centered on the relationship between the condition to systemic connective tissue disorders such as Marfan syndrome (2) and Ehlers-Danlos syndrome (3). Although the molecular mechanism underlying nonsyndromic aortic aneurysm is complex and has not been determined definitively, several risk factors, including age, arteriosclerosis, hypertension and inflammatory or autoimmune diseases that affect the aorta, have been identified clinically $(4,5)$. In addition to these conventional risk factors, recent studies have shown the importance of genetic factors in the development of sporadic aortic aneurysm by revealing a heritability of $70 \%$ (6). Genomewide association studies (GWASs) have uncovered several loci and genes that confer susceptibility to aortic aneurysm in European ancestry populations (7-12), but genetic variants that contribute to the development of this condition in Japanese individuals have not been identified definitively.

Genetic variants previously associated with aortic aneurysm typically have a minor allele frequency (MAF) of $>10 \%$ and a small individual effect size (7-12). Given that these common variants explain only a small fraction of disease heritability, low-frequency (MAF of $0.5-5 \%$ ) or rare (MAF of $<0.5 \%$ ) variants with a larger effect size may contribute to the genetic architecture of aortic aneurysm (13).

In the present study, we performed exome-wide association studies (EWASs) with the use of exome array-based genotyping methods to identify single nucleotide polymorphisms (SNPs) - in particular, low-frequency or rare coding variants with a moderate to large effect size - that confer susceptibility to aortic aneurysm in Japanese individuals. Given that most low-frequency or rare variants were not included in the arrays of previous GWASs, we used Illumina HumanExome-12 DNA Analysis BeadChip or Infinium Exome-24 BeadChip arrays, which provide coverage for functional SNPs including low-frequency or rare variants in entire exons.

\section{Materials and methods}

Study population. A total of 8,782 Japanese individuals (456 patients with aortic aneurysm, 8,326 controls) was examined. The subjects were recruited from individuals who visited outpatient clinics of or were admitted to participating hospitals (Gifu Prefectural Tajimi Hospital, Tajimi; Gifu Prefectural General Medical Center, Gifu; Japanese Red Cross Nagoya First Hospital, Nagoya; Inabe General Hospital, Inabe; Hirosaki University Hospital and Hirosaki Stroke and Rehabilitation Center, Hirosaki) either because they were experiencing various symptoms or for an annual health checkup between 2002 and 2014; from community-dwelling individuals recruited to a population-based cohort study in Inabe between 2010 and 2014 or in Tokyo or Kusatsu between 2011 and 2015; or from individuals who underwent autopsy at Tokyo Metropolitan Geriatric Hospital from 1995 to 2012.

True aortic aneurysm was defined as a permanent localized dilation of the aorta with $a \geq 50 \%$ increase in diameter relative to the expected normal size of the artery or with a diameter of $>5 \mathrm{~cm}$ (14). Dissecting aortic aneurysm was defined as separation of the aortic wall layers with resulting true and false lumens or as intramural hematoma (15). The subjects with aortic aneurysm (279 with true aneurysm and 181 with dissecting aneurysm (four had both conditions) were examined by chest and abdominal X-ray and echocardiography followed by contrast medium-enhanced computed tomography. Some subjects were also examined by aortic angiography. Individuals with Marfan syndrome, Ehlers-Danlos syndrome, bicuspid aortic valve disease, aortitis syndrome, connective tissue disorder, congenital malformations of the heart or vessels, pseudoaneurysm, or traumatic aneurysm were excluded from the study. The control individuals had no history of aortic, coronary, or peripheral arterial disease; ischemic or hemorrhagic stroke; intracranial aneurysm; or other atherosclerotic, thrombotic, embolic or hemorrhagic disorders. Autopsy cases without aortic aneurysm were excluded from controls.

The study protocol complied with the Declaration of Helsinki and was approved by the Committees on the Ethics of Human Research of Mie University Graduate School of Medicine, Hirosaki University Graduate School of Medicine, Tokyo Metropolitan Institute of Gerontology, and participating hospitals. Written informed consent was obtained from each participant or from families of the deceased subjects.

EWASs. Venous blood (5 or $7 \mathrm{ml})$ was collected into tubes containing $50 \mathrm{mmol} / \mathrm{l}$ ethylenediaminetetraacetic acid (disodium salt), peripheral blood leukocytes were isolated, and genomic DNA was extracted from these cells either with the use of a DNA extraction kit (Genomix supplied by Talent, Trieste, Italy, or SMITEST EX-R\&D supplied by Medical and Biological Laboratories, Nagoya, Japan) or by standard protocols based on phenol-chloroform extraction and spin columns. In autopsy cases, genomic DNA was extracted from kidneys. EWASs were performed for the 456 subjects with aortic aneurysm (or for the 279 subjects with true aneurysm or 181 subjects with dissecting aneurysm) and the 8,326 control subjects with the use of a HumanExome-12 v1.1 or v1.2 DNA Analysis BeadChip or an Infinium Exome-24 v1.0 BeadChip (Illumina, San Diego, CA, USA). These exome arrays include putative functional exonic variants selected from $>12,000$ individual exome or whole-genome sequences. The exonic content consists of $\sim 244,000$ SNPs representing diverse populations, including European, African, Chinese and Hispanic individuals (16). SNPs contained in only one of the exome arrays $(\sim 3.6 \%)$ were excluded from analysis. We performed quality control (17) as follows. i) Genotyping data with a call rate of $<97 \%$ were discarded, with the mean call rate for the remaining data being $99.9 \%$. ii) Gender specification was checked for each sample, with samples for which the gender designation in the clinical records was inconsistent with genetic sex being discarded. iii) Duplicated samples and cryptic relatedness were checked by calculation of identity by descent; all pairs with DNA samples showing identity by descent of $>0.1875$ were inspected and one sample from each pair was excluded. iv) The frequency of heterozygosity of SNPs was calculated for all samples, with those found to have extremely low or high heterozygosity ( $>3$ standard deviations from the mean) being discarded. v) SNPs in sex chromosomes or mitochondrial DNA were excluded from the analysis, as 


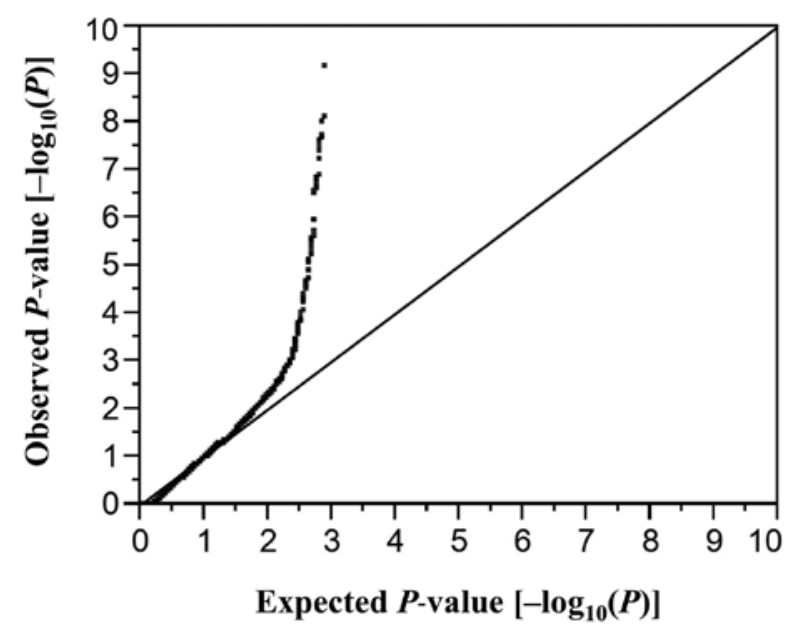

Figure 1. Quantile-quantile plot for P-values of allele frequencies in the exome-wide association study (EWAS) of aortic aneurysm. The observed $\mathrm{P}$-values ( $\mathrm{y}$-axis) are compared with the expected $\mathrm{P}$-values (x-axis) under the null hypothesis, with the values being plotted as $-\log _{10}(\mathrm{P})$.

were nonpolymorphic SNPs or SNPs with a MAF of $<0.1 \%$. vi) SNPs whose genotype distributions in control individuals deviated significantly $(\mathrm{P}<0.001)$ from Hardy-Weinberg equilibrium were excluded. vii) The genotype data for each EWAS were examined for population stratification by principal components analysis (18), and population outliers were excluded from the analysis. A total of 41,432 SNPs passed quality control and was subjected to analysis.

Statistical analysis. Quantitative data for characteristics of the study subjects were compared between patients with aortic aneurysm and control individuals with the unpaired Student's $\mathrm{t}$ test. Categorical data were compared between the two groups with Fisher's exact test. Allele frequencies were estimated by the gene counting method, and Fisher's exact test was applied to identify departure from Hardy-Weinberg equilibrium. Allele frequencies of SNPs were compared between patients with aortic aneurysm and control subjects with Fisher's exact test. Multivariable logistic regression analysis was performed with aortic aneurysm as a dependent variable and independent variables including age, gender ( 0 , woman; 1 , man), the prevalence of hypertension ( 0 , no history of this condition; 1 , positive history), and genotype of each SNP. Genotypes of SNPs were assessed according to dominant $[0, A A ; 1, A B+B B$ (A, major allele; $\mathrm{B}$, minor allele)], recessive $(0, \mathrm{AA}+\mathrm{AB}$; $1, \mathrm{BB})$, and additive genetic models, and the P-value, odds ratio, and $95 \%$ confidence interval were calculated. Additive models comprised additive $1(0, \mathrm{AA} ; 1, \mathrm{AB} ; 0, \mathrm{BB})$ and additive $2(0, \mathrm{AA} ; 0, \mathrm{AB} ; 1, \mathrm{BB})$ models, which were analyzed simultaneously with a single statistical model. To compensate for multiple comparisons of genotypes with aortic aneurysm, we applied Bonferroni's correction for statistical significance of association. Given that 41,432 SNPs were finally examined, a P-value of $<1.21 \times 10^{-6}(0.05 / 41,432)$ was considered statistically significant. A quantile-quantile plot for P-values of allele frequencies in the EWAS for aortic aneurysm is shown in Fig. 1. The inflation factor $(\lambda)$ was 1.57. P-values for other comparisons were similarly adjusted by Bonferroni's correc-
Table I. Characteristics of the 8,782 study subjects.

\begin{tabular}{lccr}
\hline Characteristics & $\begin{array}{c}\text { Aortic } \\
\text { aneurysm }\end{array}$ & Control & P-value \\
\hline No. of subjects & 456 & 8326 & \\
Age (years) & $74.7 \pm 13.5$ & $57.3 \pm 13.5$ & $<0.0001$ \\
Gender (male/female, \%) & $64.0 / 36.0$ & $51.4 / 48.6$ & $<0.0001$ \\
Body mass index $\left(\mathrm{kg} / \mathrm{m}^{2}\right)$ & $23.2 \pm 3.5$ & $23.1 \pm 3.5$ & 0.7068 \\
Current or former smoker (\%) & 44.1 & 39.8 & 0.1777 \\
Hypertension (\%) & 94.5 & 40.7 & $<0.0001$ \\
Diabetes mellitus (\%) & 44.7 & 14.7 & $<0.0001$ \\
Dyslipidemia (\%) & 67.9 & 56.8 & 0.0006 \\
Chronic kidney disease (\%) & 41.9 & 17.5 & $<0.0001$ \\
Hyperuricemia (\%) & 25.7 & 16.1 & 0.0003
\end{tabular}

Quantitative data are expressed as means \pm SD and were compared between patients with aortic aneurysm and control individuals with the unpaired Student's t-test. Categorical data were compared with Fisher's exact test. Based on Bonferroni's correction, a P-value of $<0.0056(0.05 / 9)$ was considered statistically significant.

tion. Statistical tests were performed with JMP Genomics version 6.0 software (SAS Institute, Cary, NC, USA).

\section{Results}

Characteristics of the subjects. The characteristics of the subjects enrolled in the study are shown in Table I. Age, the frequency of males, and the prevalence of hypertension, diabetes mellitus, dyslipidemia, chronic kidney disease and hyperuricemia were significantly greater in patients with aortic aneurysm than in control individuals.

EWAS of aortic aneurysm. We examined the correlation of allele frequencies for 41,432 SNPs that passed quality control to aortic aneurysm using the Fisher's exact test. A Manhattan plot for the EWAS of aortic aneurysm is shown in Fig. 2. After Bonferroni's correction, 59 SNPs were found to be significantly $\left(\mathrm{P}<1.21 \times 10^{-6}\right)$ associated with aortic aneurysm (Table II). The genotype distributions of these SNPs were in Hardy-Weinberg equilibrium $(\mathrm{P}>0.001)$ both among patients with aortic aneurysm and among the control individuals (data not shown).

Multivariable logistic regression analysis of the correlation of SNPs to aortic aneurysm. The relation of the 59 identified SNPs to aortic aneurysm was examined further by multivariable logistic regression analysis with adjustment for age, gender and the prevalence of hypertension. Although 8 SNPs were related $(\mathrm{P}<0.05)$ to aortic aneurysm, no SNP was significantly $\left[\mathrm{P}<2.12 \times 10^{-4}(0.05 / 236)\right]$ associated with this condition (Table III). We then examined the correlation of the 8 identified SNPs to true or dissecting aortic aneurysm separately. Five SNPs were related $(\mathrm{P}<0.05)$ to true aortic aneurysm (Table IV), among which rs1465567 [T/C (W229R)] of EGF-like, fibronectin type III, and laminin G domains gene (EGFLAM) was significantly $[\mathrm{P}<0.0016(0.05 / 32)]$ associated with this condition, with the minor $\mathrm{C}$ allele representing a risk 
Table II. The 59 single nucleotide polymorphisms (SNPs) significantly $\left(\mathrm{P}<1.21 \times 10^{-6}\right)$ associated with aortic aneurysm in an exome-wide association study (EWAS).

\begin{tabular}{|c|c|c|c|c|c|c|}
\hline Gene & dbSNP & $\begin{array}{l}\text { Nucleotide } \\
\text { (amino acid) } \\
\text { substitution }^{\mathrm{a}}\end{array}$ & $\begin{array}{l}\text { Chromosome: } \\
\text { position }\end{array}$ & $\begin{array}{l}\text { MAF } \\
(\%)\end{array}$ & $\begin{array}{l}\text { P-value } \\
\text { (allele) }\end{array}$ & $\begin{array}{c}\text { Allele } \\
\text { OR }\end{array}$ \\
\hline CATSPER4 & rs 11247866 & A/G (Q77R) & $1: 26191303$ & 0.4 & $9.82 \times 10^{-147}$ & 1.81 \\
\hline RNASE13 & rs 143881017 & $\mathrm{C} / \mathrm{T}(\mathrm{R} 140 \mathrm{H})$ & $14: 21033870$ & 0.5 & $2.49 \times 10^{-144}$ & 2.77 \\
\hline \multirow[t]{2}{*}{ RNASE10 } & rs202109789 & G/A (G87S) & $14: 20510730$ & 0.2 & $4.32 \times 10^{-123}$ & 0.47 \\
\hline & rs 2582513 & $\mathrm{~A} / \mathrm{G}$ & $14: 104948453$ & 39.9 & $1.72 \times 10^{-118}$ & 0.86 \\
\hline HEATRl & rs 193150310 & T/A (V1975D) & $1: 236554752$ & 0.3 & $3.09 \times 10^{-118}$ & 0.76 \\
\hline KIAA1217 & rs 10828663 & G/A (A807T) & $10: 24524525$ & 10.4 & $2.68 \times 10^{-100}$ & 1.00 \\
\hline MTUS1 & rs3739407 & G/A (R148C) & $8: 17755366$ & 38.4 & $2.32 \times 10^{-87}$ & 0.98 \\
\hline OR5W2 & rs 75634103 & $\mathrm{G} / \mathrm{A}$ & $11: 55914523$ & 10.4 & $2.74 \times 10^{-87}$ & 1.11 \\
\hline$A L P K 1$ & rs2074379 & A/G (I732M) & $4: 112431743$ & 32.0 & $1.03 \times 10^{-86}$ & 1.11 \\
\hline ATAD5 & rs 11657270 & $\mathrm{~T} / \mathrm{C}(\mathrm{Y} 1419 \mathrm{H})$ & $17: 30887369$ & 18.1 & $3.24 \times 10^{-64}$ & 1.13 \\
\hline$A C A T 2$ & rs 25683 & $\mathrm{~A} / \mathrm{G}(\mathrm{K} 211 \mathrm{R})$ & $6: 159775311$ & 18.8 & $1.90 \times 10^{-61}$ & 0.86 \\
\hline ZNF474 & rs201335566 & G/A (R253Q) & $5: 122152748$ & 0.5 & $4.22 \times 10^{-44}$ & 1.29 \\
\hline ZNF804B & rs6963781 & $\mathrm{A} / \mathrm{G}(\mathrm{M} 1105 \mathrm{~V})$ & $7: 89336295$ & 5.1 & $1.85 \times 10^{-42}$ & 0.90 \\
\hline LOC 100506679 & rs5751416 & $\mathrm{G} / \mathrm{A}$ & $22: 43036820$ & 26.3 & $1.62 \times 10^{-41}$ & 0.81 \\
\hline$S S P O$ & rs 191064068 & G/A (R209H) & $7: 149777738$ & 1.1 & $8.55 \times 10^{-35}$ & 1.13 \\
\hline ARHGEF 28 & rs536568 & $\mathrm{A} / \mathrm{C}$ & $5: 73935841$ & 45.8 & $3.61 \times 10^{-33}$ & 1.03 \\
\hline TMEM2 & rs 142154818 & G/A (T1062M) & $9: 71700645$ & 1.0 & $6.41 \times 10^{-33}$ & 1.90 \\
\hline$H L A-D M B$ & rs 151719 & $\mathrm{~A} / \mathrm{G}$ & $6: 32936123$ & 25.7 & $1.11 \times 10^{-30}$ & 1.03 \\
\hline \multirow{2}{*}{$C C D C 66$} & rs61747994 & $\mathrm{T} / \mathrm{C}$ (L802S) & 3:56619399 & 9.8 & $3.77 \times 10^{-30}$ & 0.92 \\
\hline & rs3135365 & $\mathrm{T} / \mathrm{G}$ & $6: 32421478$ & 18.9 & $1.62 \times 10^{-28}$ & 0.84 \\
\hline NAA25 & rs12231744 & $\mathrm{C} / \mathrm{T}(\mathrm{R} 876 \mathrm{~K})$ & 12:112039251 & 35.1 & $5.02 \times 10^{-28}$ & 1.07 \\
\hline RALGAPA2 & rs 142962992 & G/C (E1676D) & $20: 20505435$ & 0.9 & $1.77 \times 10^{-26}$ & 1.10 \\
\hline$N E U 1$ & rs 13118 & $\mathrm{~T} / \mathrm{A}$ & $6: 31859509$ & 9.7 & $6.92 \times 10^{-22}$ & 1.20 \\
\hline$A X D N D 1$ & rs41267592 & C/T (T627M) & $1: 179468524$ & 0.3 & $1.42 \times 10^{-20}$ & 0.63 \\
\hline$P H Y K P L$ & rs 146105181 & $\mathrm{~T} / \mathrm{C}(\mathrm{N} 88 \mathrm{D})$ & $5: 178230016$ & 0.2 & $2.15 \times 10^{-20}$ & 1.46 \\
\hline РCDH8 & rs5030685 & $\mathrm{A} / \mathrm{G}(\mathrm{V} 743 \mathrm{~A})$ & 13:52846209 & 0.3 & $9.92 \times 10^{-20}$ & 2.72 \\
\hline SELE & rs5361 & $\mathrm{T} / \mathrm{G}(\mathrm{S} 149 \mathrm{R})$ & $1: 1169731919$ & 3.3 & $2.49 \times 10^{-17}$ & 0.95 \\
\hline MOV1OL1 & rs760749 & $\mathrm{A} / \mathrm{C}(\mathrm{I} 454 \mathrm{~L})$ & $22: 50117257$ & 27.8 & $2.97 \times 10^{-17}$ & 1.02 \\
\hline HHLAl & rs 75623295 & C/G (T90R) & 8:132098893 & 2.9 & $1.23 \times 10^{-16}$ & 0.80 \\
\hline$T U B B 1$ & rs6070697 & G/A (R307H) & $20: 59024347$ & 12.1 & $2.17 \times 10^{-16}$ & 0.92 \\
\hline ZNF708 & rs504280 & C/T (R66Q) & $19: 21294577$ & 7.4 & $2.16 \times 10^{-15}$ & 0.96 \\
\hline$T I C R R$ & rs79501973 & G/A (V1373I) & $15: 89624427$ & 14.7 & $2.51 \times 10^{-15}$ & 0.97 \\
\hline$A D N P$ & rs 148496595 & C/G (D924E) & 20:50891942 & 0.3 & $2.71 \times 10^{-14}$ & 0.68 \\
\hline \multirow[t]{2}{*}{$F C A R$} & rs 11666735 & $\mathrm{G} / \mathrm{A}(\mathrm{D} 113 \mathrm{~N})$ & $19: 54885501$ & 3.2 & $3.10 \times 10^{-14}$ & 1.03 \\
\hline & rs2823962 & $\mathrm{G} / \mathrm{A}$ & $21: 16673913$ & 32.8 & $7.80 \times 10^{-14}$ & 0.93 \\
\hline \multirow[t]{2}{*}{ EGFLAM } & rs 1465567 & $\mathrm{~T} / \mathrm{C}(\mathrm{W} 229 \mathrm{R})$ & $5: 38370435$ & 25.1 & $5.92 \times 10^{-13}$ & 1.19 \\
\hline & rs 1480347 & $\mathrm{G} / \mathrm{A}$ & 8:20489946 & 17.3 & $3.49 \times 10^{-12}$ & 1.07 \\
\hline \multirow[t]{5}{*}{$U B E 4 B$} & rs 180983516 & G/A (R331H) & 1:10106379 & 0.8 & $4.50 \times 10^{-12}$ & 0.60 \\
\hline & rs 448705 & $\mathrm{~A} / \mathrm{G}$ & 8:17837193 & 12.4 & $5.42 \times 10^{-12}$ & 1.01 \\
\hline & rs11970286 & $\mathrm{C} / \mathrm{T}$ & $6: 118359211$ & 17.3 & $1.38 \times 10^{-11}$ & 0.90 \\
\hline & rs 10047727 & $\mathrm{~T} / \mathrm{C}$ & $13: 21743051$ & 42.7 & $6.67 \times 10^{-10}$ & 0.90 \\
\hline & rs507856 & $\mathrm{C} / \mathrm{T}$ & $3: 161736158$ & 38.3 & $7.71 \times 10^{-9}$ & 0.93 \\
\hline SLC1A6 & rs7253812 & $\mathrm{C} / \mathrm{A}$ & 19:14982691 & 26.7 & $9.43 \times 10^{-9}$ & 0.99 \\
\hline$F G B$ & rs 1800789 & $\mathrm{G} / \mathrm{A}$ & $4: 154561591$ & 13.3 & $1.86 \times 10^{-8}$ & 0.99 \\
\hline SLC9A4 & rs 1014286 & $\mathrm{~A} / \mathrm{G}(\mathrm{S} 784 \mathrm{G})$ & $2: 102532641$ & 43.9 & $1.90 \times 10^{-8}$ & 1.13 \\
\hline HECTD4 & rs 2074356 & $\mathrm{C} / \mathrm{T}$ & 12:112207597 & 25.4 & $2.22 \times 10^{-8}$ & 1.03 \\
\hline PKDIL1 & rs66755489 & G/A (P2021L) & $7: 47835032$ & 2.9 & $2.50 \times 10^{-8}$ & 1.16 \\
\hline$C A M S A P 1$ & rs201291561 & $\mathrm{T} / \mathrm{C}(\mathrm{N} 1062 \mathrm{~S})$ & $9: 135821476$ & 0.2 & $3.04 \times 10^{-8}$ & 1.14 \\
\hline C7orf43 & rs3800952 & C/T (R353Q) & $7: 100160331$ & 6.3 & $4.08 \times 10^{-8}$ & 1.08 \\
\hline
\end{tabular}


Table II. Continued.

\begin{tabular}{|c|c|c|c|c|c|c|}
\hline Gene & dbSNP & $\begin{array}{l}\text { Nucleotide } \\
\text { (amino acid) } \\
\text { substitution }^{\mathrm{a}}\end{array}$ & $\begin{array}{l}\text { Chromosome: } \\
\text { position }\end{array}$ & $\begin{array}{l}\text { MAF } \\
(\%)\end{array}$ & $\begin{array}{l}\text { P-value } \\
\text { (allele) }\end{array}$ & $\begin{array}{c}\text { Allele } \\
\text { OR }\end{array}$ \\
\hline ZNF671 & rs3746207 & G/A (A149V) & 19:57721640 & 12.6 & $5.90 \times 10^{-8}$ & 0.99 \\
\hline \multirow[t]{3}{*}{ RIN3 } & rs7150931 & $\mathrm{T} / \mathrm{C}$ & 14:92671696 & 46.2 & $1.26 \times 10^{-7}$ & 1.03 \\
\hline & rs10805579 & $\mathrm{G} / \mathrm{A}$ & $5: 19127418$ & 10.5 & $1.48 \times 10^{-7}$ & 1.03 \\
\hline & rs12546220 & $\mathrm{T} / \mathrm{C}$ & $8: 69461493$ & 29.1 & $1.82 \times 10^{-7}$ & 0.96 \\
\hline DRD2 & rs12363125 & $\mathrm{C} / \mathrm{T}$ & 11:113415194 & 6.2 & $1.89 \times 10^{-7}$ & 0.88 \\
\hline MTUS2 & rs17571410 & $\mathrm{G} / \mathrm{A}$ & 13:29007481 & 41.4 & $2.35 \times 10^{-7}$ & 0.91 \\
\hline GALNTL5 & rs11766982 & $\mathrm{A} / \mathrm{G}$ & $7: 151996417$ & 27.6 & $2.56 \times 10^{-7}$ & 1.05 \\
\hline POLE & rs5745022 & $\mathrm{C} / \mathrm{T}$ & $12: 132632393$ & 20.6 & $2.82 \times 10^{-7}$ & 0.96 \\
\hline CHAT & rs3810947 & $\mathrm{A} / \mathrm{G}$ & $10: 49613197$ & 43.0 & $3.19 \times 10^{-7}$ & 0.97 \\
\hline LILRB5 & rs117421142 & A/G (I420T) & $19: 54252383$ & 1.0 & $1.16 \times 10^{-6}$ & 1.29 \\
\hline
\end{tabular}

Allele frequencies were analyzed with Fisher's exact test. ${ }^{\mathrm{a} M a j o r}$ allele/minor allele. MAF, minor allele frequency; OR, odds ratio.

Table III. Correlation of single nucleotide polymorphisms (SNPs) to aortic aneurysm as determined by multivariable logistic regression analysis.

\begin{tabular}{|c|c|c|c|c|c|c|c|c|c|}
\hline \multirow[b]{2}{*}{ SNP } & & \multicolumn{2}{|c|}{ Dominant } & \multicolumn{2}{|c|}{ Recessive } & \multicolumn{2}{|c|}{ Additive 1} & \multicolumn{2}{|c|}{ Additive 2} \\
\hline & & P-value & $\begin{array}{c}\text { OR } \\
(95 \% \mathrm{CI})\end{array}$ & $\mathrm{P}$-value & $\begin{array}{c}\text { OR } \\
(95 \% \mathrm{CI})\end{array}$ & P-value & $\begin{array}{c}\text { OR } \\
(95 \% \mathrm{CI})\end{array}$ & P-value & $\begin{array}{c}\text { OR } \\
(95 \% \mathrm{CI})\end{array}$ \\
\hline rs 143881017 & $\mathrm{C} / \mathrm{T}(\mathrm{R} 140 \mathrm{H})$ & 0.0208 & $3.00(1.20-6.80)$ & 0.9665 & & 0.0207 & $3.00(1.20-6.79)$ & 0.9667 & \\
\hline rs5751416 & $\mathrm{G} / \mathrm{A}$ & 0.0351 & $0.79(0.63-0.98)$ & 0.2034 & & 0.0697 & & 0.1055 & \\
\hline rs 142154818 & $\mathrm{G} / \mathrm{A}(\mathrm{T} 1062 \mathrm{M})$ & 0.0486 & $1.94(1.00-3.50)$ & 0.7044 & & 0.0452 & $1.97(1.02-3.54)$ & 0.7078 & \\
\hline rs 13118 & $\mathrm{~T} / \mathrm{A}$ & 0.0415 & $1.32(1.01-1.71)$ & 0.4182 & & 0.0245 & $1.37(1.04-1.78)$ & 0.4879 & \\
\hline rs5030685 & A/G (V743A) & 0.0293 & $2.94(1.13-6.76)$ & 0.6067 & & 0.0227 & $3.12(1.19-7.22)$ & 0.6090 & \\
\hline rs1465567 & T/C (W229R) & 0.0004 & $1.49(1.19-1.85)$ & 0.6932 & & 0.0004 & $1.51(1.20-1.90)$ & 0.2807 & \\
\hline rs7253812 & $\mathrm{C} / \mathrm{A}$ & 0.0834 & & 0.0543 & & 0.0189 & $1.31(1.05-1.65)$ & 0.1650 & \\
\hline rs7150931 & $\mathrm{T} / \mathrm{C}$ & 0.5033 & & 0.0224 & $1.36(1.04-1.75)$ & 0.9225 & & 0.0586 & \\
\hline
\end{tabular}

Multivariable logistic regression analysis was performed with adjustment for age, gender and the prevalence of hypertension. Based on Bonferroni's correction, a P-value of $<2.12 \times 10^{-4}(0.05 / 236)$ was considered statistically significant. OR, odds ratio; CI, confidence interval.

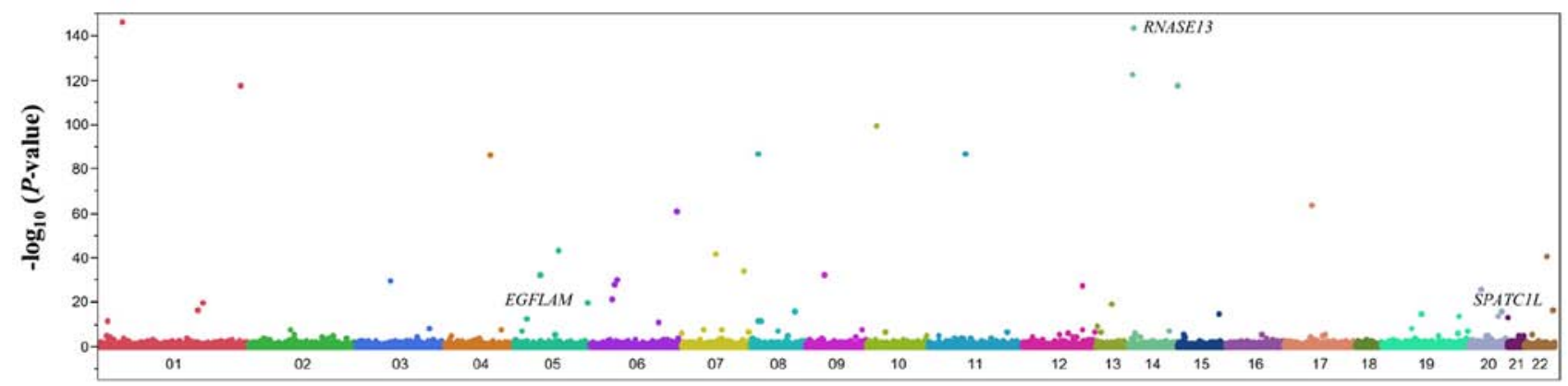

Figure 2. Manhattan plot for P-values of allele frequencies in the exome-wide association study (EWAS) of aortic aneurysm. The P-values (y-axis) are shown as $-\log _{10}(\mathrm{P})$ with respect to the physical chromosomal position of the corresponding single nucleotide polymorphism (SNP) (x-axis). The three SNPs ultimately found to be significantly associated with true aortic aneurysm (EGFLAM, SPATC1L) or dissecting aneurysm (RNASE13) are indicated.

factor. No SNP was found to be related to dissecting aortic aneurysm (data not shown).
EWASs of true or dissecting aortic aneurysm. We next examined the relation of allele frequencies for the total of 
Table IV. Correlation of single nucleotide polymorphisms (SNPs) to true aortic aneurysm as determined by multivariable logistic regression analysis.

\begin{tabular}{|c|c|c|c|c|c|c|c|c|}
\hline \multirow[b]{2}{*}{ SNP } & & \multicolumn{2}{|r|}{ Dominant } & \multicolumn{2}{|c|}{ Recessive } & \multicolumn{2}{|c|}{ Additive 1} & Additive 2 \\
\hline & & P-value & $\begin{array}{c}\text { OR } \\
(95 \% \mathrm{CI})\end{array}$ & P-value & $\begin{array}{c}\text { OR } \\
(95 \% \mathrm{CI})\end{array}$ & P-value & $\begin{array}{c}\text { OR } \\
(95 \% \mathrm{CI})\end{array}$ & $\begin{array}{c}\text { OR } \\
\text { P-value }(95 \% \mathrm{CI})\end{array}$ \\
\hline rs143881017 & $\mathrm{C} / \mathrm{T}(\mathrm{R} 140 \mathrm{H})$ & 0.2899 & & ND & & 0.2899 & & ND \\
\hline rs5751416 & $\mathrm{G} / \mathrm{A}$ & 0.0448 & $0.73(0.54-0.99)$ & 0.1221 & & 0.1030 & & 0.0663 \\
\hline rs142154818 & $\mathrm{G} / \mathrm{A}(\mathrm{T} 1062 \mathrm{M})$ & 0.2214 & & 0.8209 & & 0.2154 & & 0.8231 \\
\hline rs13118 & $\mathrm{T} / \mathrm{A}$ & 0.0253 & $1.51(1.05-2.14)$ & 0.6076 & & 0.0167 & $1.57(1.09-2.23)$ & 0.6967 \\
\hline rs5030685 & A/G (V743A) & 0.0779 & & 0.7314 & & 0.0667 & & 0.7333 \\
\hline rs1465567 & $\mathrm{T} / \mathrm{C}(\mathrm{W} 229 \mathrm{R})$ & 0.0014 & $1.63(1.21-2.21)$ & 0.6670 & & 0.0014 & $1.66(1.22-2.27)$ & 0.2911 \\
\hline rs7253812 & $\mathrm{C} / \mathrm{A}$ & 0.0122 & $1.47(1.09-1.99)$ & 0.2265 & & 0.0032 & $1.60(1.17-2.18)$ & 0.5864 \\
\hline rs7150931 & $\mathrm{T} / \mathrm{C}$ & 0.7329 & & 0.0431 & $1.45(1.01-2.04)$ & 0.2737 & & 0.2350 \\
\hline
\end{tabular}

Multivariable logistic regression analysis was performed with adjustment for age, gender and the prevalence of hypertension. Based on Bonferroni's correction, P-values of $<0.0016(0.05 / 32)$ were considered statistically significant and are shown in bold. OR, odds ratio; CI, confidence interval; ND, not determined.

41,432 SNPs to true or dissecting aortic aneurysm separately with the use of Fisher's exact test. After Bonferroni's correction, 45 or 19 SNPs were found to be significantly $\left(\mathrm{P}<1.21 \times 10^{-6}\right)$ associated with true (Table V) or dissecting (Table VI) aortic aneurysm, respectively. The genotype distributions of these SNPs were in Hardy-Weinberg equilibrium $(\mathrm{P}>0.001)$ both among patients with true or dissecting aortic aneurysm and among control individuals (data not shown).

Multivariable logistic regression analysis of the correlation of SNPs to true or dissecting aortic aneurysm. The corrrelation of the 45 identified SNPs to true aortic aneurysm was examined further by multivariable logistic regression analysis with adjustment for age, gender and the prevalence of hypertension. Among these SNPs, rs113710653 [C/T (E231K)] of the spermatogenesis and centriole-associated 1-like gene (SPATC1L) was significantly $\left[\mathrm{P}<2.78 \times 10^{-4}(0.05 / 180)\right]$ associated with true aortic aneurysm, with the minor $\mathrm{T}$ allele representing a risk factor for this condition (Table VII). The correlation of the 19 identified SNPs to dissecting aortic aneurysm was also further examined by multivariable logistic regression analysis with adjustment for age, gender and the prevalence of hypertension. The SNP rs143881017 [C/T (R140H)] of the ribonuclease A family member 13 gene (RNASE13) was significantly $\left[\mathrm{P}<6.58 \times 10^{-4}(0.05 / 76)\right]$ associated with dissecting aortic aneurysm, with the minor $\mathrm{T}$ allele representing a risk factor for this condition (Table VII).

Correlation of SNPs to intermediate phenotypes of aortic aneurysm. Finally, we examined the correlation of three SNPs (rs1465567, rs113710653 and rs143881017) to intermediate phenotypes (hypertension, diabetes mellitus, hypertriglyceridemia, hypo-HDL-cholesterolemia, hyperLDL-cholesterolemia, chronic kidney disease, obesity and hyperuricemia) of aortic aneurysm. No SNP was found to be significantly $[\mathrm{P}<0.0021(0.05 / 24)]$ associated with intermediate phenotypes (data not shown).

\section{Discussion}

True and dissecting aneurysms of the aorta develop as a result of progressive weakening of the vessel wall. They are associated with characteristic histological features including medial degeneration, which involves degeneration and fragmentation of elastic fibers as well as loss of smooth muscle cells and an accumulation of basophilic ground substances (19). In the present study, we showed that rs1465567 [T/C (W229R)] of EGFLAM and rs113710653 [C/T (E231K)] of SPATC1L were significantly associated with true aortic aneurysm, whereas rs143881017 [C/T (R140H)] of RNASE13 was significantly associated with dissecting aortic aneurysm, in Japanese individuals. The minor alleles of these SNPs were all risk factors for these conditions.

The EGFLAM is located at chromosomal region 5p13.2-p13.1 (NCBI Gene, https://www.ncbi.nlm.nih.gov/gene) and is expressed in various tissues and organs including vascular smooth muscle (The Human Protein Atlas, http://www.proteinatlas.org). EGFLAM is an extracellular matrix-like protein that colocalizes with both dystrophin and dystroglycan to the synaptic cleft of the photoreceptor ribbon synapse in the retina and which directly interacts with dystroglycan. It plays an important role in interactions between the photoreceptor ribbon synapse and bipolar dendrites $(20,21)$, and it is implicated in defective photoreceptor synaptic function associated with congenital muscular dystrophies such as muscle-eye-brain disease caused by defective glycosylation of $\alpha$-dystroglycan (22). A genome-wide pharmacogenomics study identified EGFLAM as a potential susceptibility locus for citalopram-induced side effects (23). We have now shown that rs1465567 [T/C (W229R)] of EGFLAM was significantly associated with true aortic aneurysm, with the minor $\mathrm{C}$ allele representing a risk factor for this condition, although the molecular mechanism underlying this association remains unclear.

The SPATC1L is located at chromosomal region 21q22.3 (NCBI Gene) and is expressed in various tissues 
Table V. The 45 single nucleotide polymorphisms (SNPs) significantly $\left(\mathrm{P}<1.21 \times 10^{-6}\right)$ associated with true aortic aneurysm in an exome-wide association study (EWAS).

\begin{tabular}{|c|c|c|c|c|c|c|}
\hline Gene & $\mathrm{dbSNP}$ & $\begin{array}{l}\text { Nucleotide } \\
\text { (amino acid) } \\
\text { substitution }\end{array}$ & $\begin{array}{l}\text { Chromosome: } \\
\text { position }\end{array}$ & $\begin{array}{l}\text { MAF } \\
(\%)\end{array}$ & $\begin{array}{l}\text { P-value } \\
\text { (allele) }\end{array}$ & $\begin{array}{c}\text { Allele } \\
\text { OR }\end{array}$ \\
\hline KIAA1217 & rs 10828663 & $\mathrm{G} / \mathrm{A}(\mathrm{A} 807 \mathrm{~T})$ & $10: 24524525$ & 10.4 & $6.87 \times 10^{-94}$ & 1.14 \\
\hline$N R A P$ & rs79461687 & G/T (H1246Q) & $10: 113606247$ & 1.3 & $1.58 \times 10^{-90}$ & 1.67 \\
\hline OR5W2 & rs 75634103 & $\mathrm{G} / \mathrm{A}$ & $11: 55914523$ & 10.4 & $4.84 \times 10^{-81}$ & 1.17 \\
\hline \multirow[t]{2}{*}{ ATAD5 } & rs 11657270 & $\mathrm{~T} / \mathrm{C}(\mathrm{Y} 1419 \mathrm{H})$ & $17: 30887369$ & 18.1 & $9.29 \times 10^{-70}$ & 0.98 \\
\hline & rs9683944 & $\mathrm{A} / \mathrm{G}$ & 4:137512008 & 10.8 & $1.65 \times 10^{-56}$ & 0.83 \\
\hline TMPRSS3 & rs928302 & $\mathrm{C} / \mathrm{T}(\mathrm{V} 53 \mathrm{I})$ & $21: 42389975$ & 27.6 & $1.34 \times 10^{-52}$ & 0.99 \\
\hline ZNF804B & rs6963781 & $\mathrm{A} / \mathrm{G}(\mathrm{M} 1105 \mathrm{~V})$ & $7: 89336295$ & 5.1 & $6.67 \times 10^{-47}$ & 1.01 \\
\hline ZNF474 & rs 201335566 & $\mathrm{G} / \mathrm{A}(\mathrm{R} 253 \mathrm{Q})$ & 5:122152748 & 0.5 & $5.79 \times 10^{-42}$ & 0.84 \\
\hline LOC100506679 & rs5751416 & $\mathrm{G} / \mathrm{A}$ & $22: 43036820$ & 26.3 & $2.46 \times 10^{-26}$ & 0.71 \\
\hline ARHGEF 28 & rs536568 & $\mathrm{A} / \mathrm{C}$ & 5:73935841 & 45.8 & $3.10 \times 10^{-23}$ & 1.03 \\
\hline RALGAPA2 & rs 142962992 & $\mathrm{G} / \mathrm{C}(\mathrm{E} 1676 \mathrm{D})$ & $20: 20505435$ & 0.9 & $8.85 \times 10^{-23}$ & 0.72 \\
\hline LYSMD1 & rs79024247 & $\mathrm{G} / \mathrm{T}(\mathrm{Q} 150 \mathrm{~K})$ & $1: 151160974$ & 5.2 & $7.43 \times 10^{-21}$ & 0.88 \\
\hline CNGAl & rs 192912733 & $\mathrm{C} / \mathrm{T}(\mathrm{R} 493 \mathrm{Q})$ & 4:47937223 & 0.7 & $8.13 \times 10^{-21}$ & 1.17 \\
\hline MOVIOLI & rs 760749 & $\mathrm{~A} / \mathrm{C}(\mathrm{I} 454 \mathrm{~L})$ & $22: 50117257$ & 27.8 & $1.23 \times 10^{-20}$ & 1.18 \\
\hline$H L A-D M B$ & rs 151719 & $\mathrm{~A} / \mathrm{G}$ & $6: 32936123$ & 25.7 & $1.96 \times 10^{-19}$ & 1.17 \\
\hline \multirow[t]{2}{*}{$T U B B 1$} & rs6070697 & $\mathrm{G} / \mathrm{A}(\mathrm{R} 307 \mathrm{H})$ & $20: 59024347$ & 12.1 & $3.20 \times 10^{-18}$ & 0.97 \\
\hline & rs3135365 & $\mathrm{T} / \mathrm{G}$ & $6: 32421478$ & 18.9 & $3.94 \times 10^{-17}$ & 0.83 \\
\hline CCDC 33 & rs1484214 & $\mathrm{A} / \mathrm{C}$ & $15: 74288732$ & 49.3 & $6.60 \times 10^{-17}$ & 1.09 \\
\hline \multirow[t]{2}{*}{ ZNF708 } & rs504280 & $\mathrm{C} / \mathrm{T}$ (R66Q) & $19: 21294577$ & 7.4 & $3.03 \times 1^{0-15}$ & 0.98 \\
\hline & rs2823962 & $\mathrm{G} / \mathrm{A}$ & $21: 16673913$ & 32.8 & $3.36 \times 10^{-14}$ & 0.97 \\
\hline$S G C Z$ & rs1037934 & $\mathrm{G} / \mathrm{A}$ & 8:14399065 & 9.0 & $3.44 \times 10^{-13}$ & 1.22 \\
\hline DUOXI & rs 199549867 & $\mathrm{~A} / \mathrm{T}(\mathrm{R} 569 \mathrm{~S})$ & $15: 45141997$ & 0.2 & $1.58 \times 10^{-10}$ & 0.81 \\
\hline CTSC & rs3888798 & $\mathrm{T} / \mathrm{C}(\mathrm{I} 453 \mathrm{~V})$ & 11:88294041 & 16.5 & $3.21 \times 10^{-10}$ & 1.06 \\
\hline C10orf128 & rs118189413 & $\mathrm{C} / \mathrm{G}(\mathrm{H} 67 \mathrm{D})$ & $10: 49166908$ & 6.3 & $4.04 \times 10^{-10}$ & 0.84 \\
\hline OR5VI & rs9405124 & $\mathrm{A} / \mathrm{G}$ & $6: 29401036$ & 19.9 & $4.15 \times 10^{-10}$ & 0.98 \\
\hline$U B A P 2 L$ & rs 143080179 & $\mathrm{~T} / \mathrm{C}(\mathrm{S} 641 \mathrm{P})$ & $1: 154255163$ & 1.3 & $4.20 \times 10^{-10}$ & 0.66 \\
\hline CAMSAP1 & rs 201291561 & $\mathrm{~T} / \mathrm{C}(\mathrm{N} 1062 \mathrm{~S})$ & $9: 135821476$ & 0.2 & $5.67 \times 10^{-10}$ & 1.87 \\
\hline TICRR & rs79501973 & G/A (V1373I) & $15: 89624427$ & 14.7 & $7.76 \times 10^{-10}$ & 1.04 \\
\hline NCAMI & rs7111410 & $\mathrm{C} / \mathrm{T}$ & $11: 113178565$ & 15.9 & $2.63 \times 10^{-9}$ & 0.80 \\
\hline$I R G Q$ & $\mathrm{rs} 3817$ & $\mathrm{C} / \mathrm{A}$ & $19: 43586043$ & 47.7 & $3.30 \times 10^{-9}$ & 0.92 \\
\hline$S S P O$ & rs 191064068 & G/A (R209H) & $7: 149777738$ & 1.1 & $2.35 \times 10^{-8}$ & 1.67 \\
\hline \multirow[t]{2}{*}{ SLC9A4 } & rs 1014286 & $\mathrm{~A} / \mathrm{G}(\mathrm{S} 784 \mathrm{G})$ & $2: 102532641$ & 43.9 & $2.84 \times 10^{-8}$ & 1.11 \\
\hline & rs2138852 & $\mathrm{A} / \mathrm{G}$ & $17: 29376331$ & 2.5 & $2.92 \times 10^{-8}$ & 0.77 \\
\hline SPATC $1 L$ & rs113710653 & $\mathrm{C} / \mathrm{T}(\mathrm{E} 231 \mathrm{~K})$ & $21: 46161921$ & 1.9 & $3.91 \times 10^{-8}$ & 7.39 \\
\hline$D R D 2$ & rs 12363125 & $\mathrm{C} / \mathrm{T}$ & $11: 113415194$ & 6.2 & $4.99 \times 10^{-8}$ & 0.87 \\
\hline CCT5 & rs 201280643 & $\mathrm{C} / \mathrm{G}(\mathrm{S} 373 \mathrm{C})$ & $5: 10262584$ & 0.4 & $7.04 \times 10^{-8}$ & 0.99 \\
\hline \multirow[t]{4}{*}{$A X D N D 1$} & rs41267592 & $\mathrm{C} / \mathrm{T}(\mathrm{T} 627 \mathrm{M})$ & $1: 179468524$ & 0.3 & $7.85 \times 10^{-8}$ & 1.03 \\
\hline & rs507856 & $\mathrm{C} / \mathrm{T}$ & 3:161736158 & 38.3 & $1.10 \times 10^{-7}$ & 1.02 \\
\hline & rs962040 & $\mathrm{A} / \mathrm{G}$ & $8: 15454369$ & 30.1 & $1.21 \times 10^{-7}$ & 0.96 \\
\hline & rs11970286 & $\mathrm{C} / \mathrm{T}$ & $6: 118359211$ & 17.3 & $1.60 \times 10^{-7}$ & 0.83 \\
\hline \multirow[t]{2}{*}{$N I N L$} & rs 199671123 & $\mathrm{C} / \mathrm{T}(\mathrm{A} 796 \mathrm{~T})$ & $20: 25476905$ & 0.2 & $2.45 \times 10^{-7}$ & 0.85 \\
\hline & rs12531488 & $\mathrm{C} / \mathrm{T}$ & 7:145194993 & 16.0 & $7.91 \times 10^{-7}$ & 1.14 \\
\hline MROH7 & rs 143029488 & $\mathrm{G} / \mathrm{C}(\mathrm{A} 1313 \mathrm{P})$ & $1: 54710152$ & 0.8 & $1.05 \times 10^{-6}$ & 1.34 \\
\hline$A F A P 1$ & rs 28406288 & $\mathrm{G} / \mathrm{C}(\mathrm{C} 403 \mathrm{~S})$ & 4:7800500 & 0.1 & $1.10 \times 10^{-6}$ & ND \\
\hline GALM & rs6741892 & A/T (N190Y) & $2: 38689828$ & 20.1 & $1.12 \times 10^{-6}$ & 0.93 \\
\hline
\end{tabular}

Allele frequencies were analyzed with Fisher's exact test. ${ }^{a}$ Major allele/minor allele. MAF, minor allele frequency; OR, odds ratio; ND, not determined. 
Table VI. The 19 single nucleotide polymorphisms (SNPs) significantly $\left(\mathrm{P}<1.21 \times 10^{-6}\right)$ associated with dissecting aortic aneurysm in an exome-wide association study (EWAS).

\begin{tabular}{|c|c|c|c|c|c|c|}
\hline Gene & dbSNP & $\begin{array}{l}\text { Nucleotide } \\
\text { (amino acid) } \\
\text { substitution }^{\mathrm{a}}\end{array}$ & $\begin{array}{l}\text { Chromosome: } \\
\text { position }\end{array}$ & $\begin{array}{l}\text { MAF } \\
(\%)\end{array}$ & $\begin{array}{l}\text { P-value } \\
\text { (allele) }\end{array}$ & OR \\
\hline ATXN7 & rs3774729 & $\mathrm{G} / \mathrm{A}(\mathrm{V} 862 \mathrm{M})$ & $3: 63996406$ & 46.8 & $3.81 \times 10^{-35}$ & 0.91 \\
\hline KIAA1217 & rs 10828663 & G/A (A807T) & $10: 24524525$ & 10.4 & $1.34 \times 10^{-27}$ & 0.78 \\
\hline RNASE13 & rs 143881017 & $\mathrm{C} / \mathrm{T}(\mathrm{R} 140 \mathrm{H})$ & $14: 21033870$ & 0.5 & $5.12 \times 10^{-26}$ & 4.48 \\
\hline \multirow[t]{3}{*}{$I N P P 5 F$} & rs3736822 & A/G (I453V) & 10:119806397 & 1.7 & $8.50 \times 10^{-23}$ & 0.62 \\
\hline & rs9683944 & $\mathrm{A} / \mathrm{G}$ & $4: 137512008$ & 10.8 & $4.61 \times 10^{-17}$ & 1.17 \\
\hline & rs9610342 & $\mathrm{A} / \mathrm{G}$ & $22: 35734530$ & 30.7 & $8.20 \times 10^{-17}$ & 0.79 \\
\hline FAM98C & rs3745962 & $\mathrm{C} / \mathrm{A}(\mathrm{T} 240 \mathrm{~K})$ & $19: 38405604$ & 16.7 & $8.99 \times 10^{-15}$ & 0.96 \\
\hline \multirow[t]{2}{*}{ ZNF474 } & rs201335566 & G/A (R253Q) & $5: 122152748$ & 0.5 & $1.02 \times 10^{-12}$ & 1.95 \\
\hline & rs3135365 & $\mathrm{T} / \mathrm{G}$ & $6: 32421478$ & 18.9 & $1.21 \times 10^{-12}$ & 0.86 \\
\hline$D E P D C 7$ & rs34161108 & G/A (A192T) & $11: 33027795$ & 6.2 & $2.29 \times 10^{-12}$ & 0.74 \\
\hline ARHGEF 28 & rs536568 & $\mathrm{A} / \mathrm{C}$ & $5: 73935841$ & 45.8 & $5.53 \times 10^{-12}$ & 1.04 \\
\hline RALGPS1 & rs57728614 & G/T (G383C) & $9: 127196583$ & 9.5 & $5.73 \times 10^{-11}$ & 0.84 \\
\hline$A I M I L$ & rs34370465 & $\mathrm{C} / \mathrm{T}(\mathrm{R} 847 \mathrm{H})$ & $1: 26344118$ & 23.9 & $3.63 \times 10^{-10}$ & 1.09 \\
\hline$A N X A 7$ & rs 3750575 & C/T (R419Q) & 10:73378933 & 5.7 & $4.20 \times 10^{-10}$ & 1.06 \\
\hline \multirow[t]{2}{*}{$A X D N D 1$} & rs41267592 & $\mathrm{C} / \mathrm{T}(\mathrm{T} 627 \mathrm{M})$ & $1: 179468524$ & 0.3 & $1.77 \times 10^{-8}$ & $\mathrm{ND}$ \\
\hline & rs2138852 & $\mathrm{A} / \mathrm{G}$ & $17: 29376331$ & 2.5 & $1.49 \times 10^{-7}$ & 1.32 \\
\hline CHAT & rs 78925077 & $\mathrm{C} / \mathrm{G}(\mathrm{S} 119 \mathrm{R})$ & 10:49622109 & 0.5 & $1.50 \times 10^{-7}$ & 1.93 \\
\hline GPR156 & rs902790 & $\mathrm{A} / \mathrm{T}(\mathrm{E} 512 \mathrm{D})$ & $3: 120167929$ & 4.8 & $2.24 \times 10^{-7}$ & 0.71 \\
\hline SELE & rs5361 & $\mathrm{T} / \mathrm{G}(\mathrm{S} 149 \mathrm{R})$ & 1:169731919 & 3.3 & $3.58 \times 10^{-7}$ & 0.98 \\
\hline
\end{tabular}

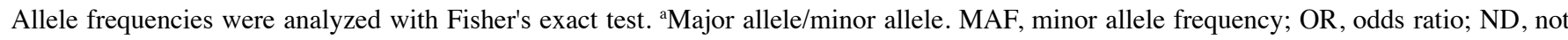
determined.

Table VII. Relation of single nucleotide polymorphisms (SNPs) to true or dissecting aortic aneurysm as determined by multivariable logistic regression analysis.

\begin{tabular}{|c|c|c|c|c|c|c|c|c|}
\hline \multirow[b]{2}{*}{ SNP } & \multicolumn{2}{|c|}{ Dominant } & \multicolumn{2}{|c|}{ Recessive } & \multicolumn{2}{|c|}{ Additive 1} & \multicolumn{2}{|c|}{ Additive 2} \\
\hline & P-value & $\begin{array}{c}\text { OR } \\
(95 \% \mathrm{CI})\end{array}$ & $\mathrm{P}$-value & $\begin{array}{c}\text { OR } \\
(95 \% \mathrm{CI})\end{array}$ & P-value & $\begin{array}{c}\text { OR } \\
(95 \% \mathrm{CI})\end{array}$ & $\mathrm{P}$-value & $\begin{array}{c}\mathrm{OR} \\
(95 \% \mathrm{CI})\end{array}$ \\
\hline $\begin{array}{l}\text { True aortic aneurysm } \\
\text { rs113710653 C/T (E231K) }\end{array}$ & 0.0002 & $5.32(2.33-11.14)$ & 0.9263 & & 0.0002 & $5.34(2.34-11.18)$ & 0.9299 & \\
\hline $\begin{array}{l}\text { Dissecting aortic aneurysm } \\
\text { rs143881017 C/T (R140H) }\end{array}$ & 0.0006 & $5.77(2.25-12.95)$ & 0.9615 & & 0.0006 & $5.48(2.26-12.97)$ & 0.9621 & \\
\hline
\end{tabular}

Multivariable logistic regression analysis was performed with adjustment for age, gender and the prevalence of hypertension. Based on Bonferroni's correction, P-values of $<2.78 \times 10^{-4}(0.05 / 180)$ or $<6.58 \times 10^{-4}(0.05 / 76)$ were considered statistically significant for true or dissecting aortic aneurysm, respectively, and are shown in bold. OR, odds ratio; CI, confidence interval.

and organs including vascular smooth muscle (The Human Protein Atlas). SPATC1L is distributed in the cytoplasm, nucleus, and perinuclear region of cells, and it translocates to the sites of cell-cell junctions in response to stimulation of cells with the neuropeptide neurokinin A (24). Expression of SPATC1L was also found to modulate the response of cells to $N$-methyl- $N$ '-nitro- $N$-nitrosoguanidine and may thereby protect cells from cell death induced by this DNA-damaging agent (25). We demonstrated that rs113710653 [C/T (E231K)] of SPATC1L was significantly associated with true aortic aneurysm, with the minor $\mathrm{T}$ allele representing a risk factor for this condition, although the functional relevance of this association remains to be elucidated.

RNASE13 is located at chromosomal region $14 \mathrm{q} 11.2$ (NCBI Gene) and is expressed at a high level in the epididymis (The Human Protein Atlas). A GWAS showed that an SNP 
(rs3748348) located in the vicinity of RNASE13 was associated with executive functioning resilience (26). Gene-based analyses also revealed a genome-wide significant association between RNASE13 and executive functioning resilience (27). We now showed that rs143881017 [C/T (R140H)] of RNASE13 was significantly associated with dissecting aortic aneurysm, with the minor $\mathrm{T}$ allele representing a risk factor for this condition, although the molecular mechanism underpinning this association remains unknown.

Previous GWASs identified the SNPs: rs10757278 of CDKN2BAS, rs7025486 of DAP2IP, rs1466535 of LRPI, rs2118181 of $F B N 1$, rs6511720 of $L D L R$ and rs599839 of SORT1 as susceptibility loci for aortic aneurysm (7-12). The MAFs of these SNPs were $>10 \%$, and the odds ratios were $0.8-1.8$ (5.7-12.28). We now identified three novel loci that may confer susceptibility to true or dissecting aortic aneurysm, with the odds ratios (MAF, \%) of rs1465567 of EGFLAM, rs113710653 of SPATC1L, and rs143881017 of RNASE13 being $1.63(25.1 \%), 5.32(1.9 \%)$, and 5.77 (0.5\%), respectively. Although rs1465567 of EGFLAM was a common variant with a small effect size, rs113710653 of SPATC1L and rs143881017 of RNASE13 were low-frequency variants with moderate to large effect sizes.

There are some limitations to the present study: i) Given that the number of subjects with aortic aneurysm was relatively small and the results of the study were not replicated, our findings will require validation with other independent subject panels or in other ethnic groups. ii) It is possible that rs1465567 of EGFLAM, rs113710653 of SPATC1L, or rs143881017 of RNASE13 is in linkage disequilibrium with other polymorphisms in the same gene or in other nearby genes that are actually responsible for the development of true or dissecting aneurysm. iii) The functional relevance of these SNPs to the pathogenesis of true or dissecting aneurysm remains to be elucidated.

In conclusion, rs1465567 of EGFLAM and rs113710653 of SPATC1L may be susceptibility loci for true aortic aneurysm and rs143881017 of RNASE13 may be such a locus for dissecting aortic aneurysm in Japanese individuals. Determination of genotypes for these SNPs may prove informative for assessment of the genetic risk for these conditions in Japanese individuals.

\section{Acknowledgements}

The present study was supported by CREST (H25-H30), Japan Science and Technology Agency (to Y.Y., J.S. and I.T.) and by Japan Society for the Promotion of Science KAKENHI grants JP15H04772 (to Y.Y.), JP25242062 (to M.T.) and JP16H01872 (to M.T.).

\section{References}

1. Chiesa R, Melissano G, Civilini E, de Moura ML, Carozzo A and Zangrillo A: Ten years experience of thoracic and thoracoabdominal aortic aneurysm surgical repair: Lessons learned. Ann Vasc Surg 18: 514-520, 2004.

2. Mizuguchi T, Collod-Beroud G, Akiyama T, Abifadel M, Harada N, Morisaki T, Allard D, Varret M, Claustres M, Morisaki H, et al: Heterozygous TGFBR2 mutations in Marfan syndrome. Nat Genet 36: 855-860, 2004.
3. Schwarze U, Schievink WI, Petty E, Jaff MR, BabovicVuksanovic D, Cherry KJ, Pepin $\mathrm{M}$ and Byers $\mathrm{PH}$ : Haploinsufficiency for one COL3A1 allele of type III procollagen results in a phenotype similar to the vascular form of EhlersDanlos syndrome, Ehlers-Danlos syndrome type IV. Am J Hum Genet 69: 989-1001, 2001.

4. Nordon IM, Hinchliffe RJ, Loftus IM and Thompson MM: Pathophysiology and epidemiology of abdominal aortic aneurysms. Nat Rev Cardiol 8: 92-102, 2011.

5. Ye Z, Austin E, Schaid DJ and Kullo IJ: A multi-locus genetic risk score for abdominal aortic aneurysm. Atherosclerosis 246: 274-279, 2016.

6. Harrison SC, Holmes MV, Agu O and Humphries SE: Genome wide association studies of abdominal aortic aneurysms - biological insights and potential translation applications. Atherosclerosis 217: 47-56, 2011

7. Helgadottir A, Thorleifsson G, Magnusson KP, Grétarsdottir S, Steinthorsdottir V, Manolescu A, Jones GT, Rinkel GJ, Blankensteijn JD, Ronkainen A, et al: The same sequence variant on 9p21 associates with myocardial infarction, abdominal aortic aneurysm and intracranial aneurysm. Nat Genet 40: 217-224, 2008.

8. Gretarsdottir S, Baas AF, Thorleifsson G, Holm H, den Heijer M, de Vries JP, Kranendonk SE, Zeebregts CJ, van Sterkenburg SM, Geelkerken RH, et al: Genome-wide association study identifies a sequence variant within the DAB2IP gene conferring susceptibility to abdominal aortic aneurysm. Nat Genet 42: 692-697, 2010.

9. Bown MJ, Jones GT, Harrison SC, Wright BJ, Bumpstead S, Baas AF, Gretarsdottir S, Badger SA, Bradley DT, Burnand K, et al; CARDIoGRAM Consortium; Global BPgen Consortium; DIAGRAM Consortium; VRCNZ Consortium: Abdominal aortic aneurysm is associated with a variant in low-density lipoprotein receptor-related protein 1. Am J Hum Genet 89: 619-627, 2011.

10. LeMaire SA, McDonald ML, Guo DC, Russell L, Miller CC III, Johnson RJ, Bekheirnia MR, Franco LM, Nguyen M, Pyeritz RE, et al: Genome-wide association study identifies a susceptibility locus for thoracic aortic aneurysms and aortic dissections spanning FBN1 at 15q21.1. Nat Genet 43: 996-1000, 2011.

11. Bradley DT, Hughes AE, Badger SA, Jones GT, Harrison SC, Wright BJ, Bumpstead S, Baas AF, Grétarsdóttir S, Burnand K, et al: A variant in LDLR is associated with abdominal aortic aneurysm. Circ Cardiovasc Genet 6: 498-504, 2013.

12. Jones GT, Bown MJ, Gretarsdottir S, Romaine SP, Helgadottir A, Yu G, Tromp G, Norman PE, Jin C, Baas AF, et al: A sequence variant associated with sortilin-1 (SORT1) on 1p13.3 is independently associated with abdominal aortic aneurysm. Hum Mol Genet 22: 2941-2947, 2013.

13. Manolio TA, Collins FS, Cox NJ, Goldstein DB, Hindorff LA, Hunter DJ, McCarthy MI, Ramos EM, Cardon LR, Chakravarti A, et al: Finding the missing heritability of complex diseases. Nature 461: 747-753, 2009.

14. Johnston KW, Rutherford RB, Tilson MD, Shah DM, Hollier L and Stanley JC: Suggested standards for reporting on arterial aneurysms. Subcommittee on Reporting Standards for Arterial Aneurysms, Ad Hoc Committee on Reporting Standards, Society for Vascular Surgery and North American Chapter, International Society for Cardiovascular Surgery. J Vasc Surg 13: 452-458, 1991.

15. Olsson C, Thelin S, Ståhle E, Ekbom A and Granath F: Thoracic aortic aneurysm and dissection: Increasing prevalence and improved outcomes reported in a nationwide population-based study of more than 14,000 cases from 1987 to 2002. Circulation 114: 2611-2618, 2006.

16. Grove ML, Yu B, Cochran BJ, Haritunians T, Bis JC, Taylor KD, Hansen M, Borecki IB, Cupples LA, Fornage M, et al: Best practices and joint calling of the HumanExome BeadChip: The CHARGE Consortium. PLoS One 8: e68095, 2013.

17. Anderson CA, Pettersson FH, Clarke GM, Cardon LR, Morris AP and Zondervan KT: Data quality control in genetic case-control association studies. Nat Protoc 5: 1564-1573, 2010.

18. Price AL, Patterson NJ, Plenge RM, Weinblatt ME, Shadick NA and Reich D: Principal components analysis corrects for stratification in genome-wide association studies. Nat Genet 38: 904-909, 2006.

19. Barbour JR, Spinale FG and Ikonomidis JS: Proteinase systems and thoracic aortic aneurysm progression. J Surg Res 139: 292-307, 2007. 
20. Sato S, Omori Y, Katoh K, Kondo M, Kanagawa M, Miyata K, Funabiki K, Koyasu T, Kajimura N, Miyoshi T, et al: Pikachurin, a dystroglycan ligand, is essential for photoreceptor ribbon synapse formation. Nat Neurosci 11: 923-931, 2008.

21. Kanagawa M, Omori Y, Sato S, Kobayashi K, Miyagoe-Suzuki Y Takeda S, Endo T, Furukawa T and Toda T: Post-translational maturation of dystroglycan is necessary for pikachurin binding and ribbon synaptic localization. J Biol Chem 285: 31208-31216, 2010.

22. Hu H, Li J, Zhang Z and Yu M: Pikachurin interaction with dystroglycan is diminished by defective O-mannosyl glycosylation in congenital muscular dystrophy models and rescued by LARGE overexpression. Neurosci Lett 489: 10-15, 2011.

23. Adkins DE, Clark SL, Åberg K, Hettema JM, Bukszár J, McClay JL, Souza RP and van den Oord EJ: Genome-wide pharmacogenomic study of citalopram-induced side effects in STAR*D. Transl Psychiatry 2: e129, 2012.

24. Lecat S, Matthes HW, Pepperkok R, Simpson JC and Galzi JL: A fluorescent live imaging screening assay based on translocation criteria identifies novel cytoplasmic proteins implicated in $\mathrm{G}$ protein-coupled receptor signaling pathways. Mol Cell Proteomics 14: 1385-1399, 2015.
25. Fry RC,Svensson JP, Valiathan C,WangE,Hogan BJ,Bhattacharya S, Bugni JM, Whittaker CA and Samson LD: Genomic predictors of interindividual differences in response to DNA damaging agents. Genes Dev 22: 2621-2626, 2008.

26. Mukherjee S, Kim S, Gibbons LE, Nho K, Risacher SL, Glymour MM, Habeck C, Lee GJ, Mormino E, Ertekin-Taner N, et al; Alzheimer's Disease Neuroimaging Initiative: Genetic architecture of resilience of executive functioning. Brain Imaging Behav 6: 621-633, 2012

27. Mukherjee S, Kim S, Ramanan VK, Gibbons LE, Nho K, Glymour MM, Ertekin-Taner N, Montine TJ, Saykin AJ and Crane PK; Alzheimer's Disease Neuroimaging Initiative: Gene-based GWAS and biological pathway analysis of the resilience of executive functioning. Brain Imaging Behav 8: 110-118, 2014.

28. van't Hof FN, Ruigrok YM, Lee CH, Ripke S, Anderson G, de Andrade M, Baas AF, Blankensteijn JD, Böttinger EP, Bown MJ, et al; Aneurysm Consortium; Vascular Research Consortium of New Zealand: Shared genetic risk factors of intracranial, abdominal, and thoracic aneurysms. J Am Heart Assoc 5: $\mathrm{e} 002603,2016$. 